\title{
Co-pyrolysis of South African bituminous coal and Scenedesmus microalgae: Kinetics and synergistic effects study
}

\author{
Bothwell Nyoni ${ }^{1}$ (i) $\cdot$ Sifundo Duma ${ }^{2}$ Lukanyo Bolo ${ }^{1} \cdot$ Shaka Shabangu $^{2} \cdot$ \\ Shanganyane P. Hlangothi ${ }^{1}$
}

Received: 25 September 2019/Revised: 19 February 2020/ Accepted: 13 March 2020/Published online: 21 March 2020

(C) The Author(s) 2020

\begin{abstract}
In this work, the co-pyrolysis of coal and algae is explored with special emphasis on decomposition kinetics and the possibility of the existence of synergistic effects. Modelling and kinetics analysis based approaches were used for the investigation of the existence of synergistic effects. The co-pyrolysis kinetics was studied using the model-free, CoatsRedfern integral method. The kinetics were evaluated for 1 st and 2 nd order reaction models. Results reveal that Scenedesmus microalgae is characterised by a two stage decomposition process that occurs at temperature ranges of $200-400{ }^{\circ} \mathrm{C}$ and 500-700 ${ }^{\circ} \mathrm{C}$ with activation energy of 145.5 and $127.3 \mathrm{~kJ} / \mathrm{mol}$, respectively. Bituminous coal has a two stage, slow decomposition process that occurs at temperature ranges of $400-700{ }^{\circ} \mathrm{C}$ and above $750{ }^{\circ} \mathrm{C}$ with an activation energy of 81.8 and $649.3 \mathrm{~kJ} / \mathrm{mol}$, respectively. Furthermore, co-pyrolysis of coal and microalgae is characterised by three stages whose kinetics are dominated by the pyrolysis of the individual materials. For the studied range of coal/algae ratios, the three pyrolysis stages occur in the approximate temperature ranges of $200-400{ }^{\circ} \mathrm{C}, 430-650{ }^{\circ} \mathrm{C}$ and above $750{ }^{\circ} \mathrm{C}$, with activation energies in the ranges of 131-138, 72-78 and $864.5-1235 \mathrm{~kJ} / \mathrm{mol}$, respectively. Modelling and kinetics study showed that there is strong evidence of interactions between coal and microalgae that manifest as synergistic effects especially in the second and third stages of decomposition.
\end{abstract}

Keywords Coal $\cdot$ Coats-Redfern $\cdot$ Kinetics $\cdot$ Microalgae $\cdot$ Synergistic effects

List of symbols $\quad t \quad$ Time

$\beta \quad$ Heating rate

TGA Thermo gravimetric analysis

A Pre-exponential factor in the Arrhenius equation $\quad w \quad$ Instantaneous mass

ASTM American society for testing and materials $\quad w_{\mathrm{i}} \quad$ Initial mass

DTG Derivative thermo gravimetric $\quad w_{\mathrm{f}} \quad$ Final mass

$E_{\mathrm{a}} \quad$ Activation energy $\quad X \quad$ Fraction of solid that has decomposed

$\mathrm{H} / \mathrm{C} \quad$ Elemental hydrogen to carbon ratio $\quad Y \quad$ Instantaneous reactivity

$k \quad$ Rate constant

$n \quad$ Order of reaction

$\mathrm{O} / \mathrm{C} \quad$ Elemental oxygen to carbon ratio

$R \quad$ Universal gas constant

Bothwell Nyoni

s215391977@mandela.ac.za; beenyoni@gmail.com

1 Department of Chemistry, Nelson Mandela University, P.O. Box 77000, Port Elizabeth 6031, South Africa

2 Innoventon, Downstream Chemicals Technology Station, Nelson Mandela University, 1-12 Gomery Ave, Summerstrand, Port Elizabeth 6031, South Africa

\section{Introduction}

The use of coal as the main energy source is expected to decline due to two major reasons. Firstly, coal is a nonrenewable resource and the current world coal reserve is getting depleted. Secondly, the emissions associated with the use of coal are believed to be the major contributor to global warming and hence climate change (Mckendry 2002). Biomass is a renewable resource that can be used as 
an alternative solid fuel. Biomass comes in different types, for example, woody plants, aquatic plants (algae) and human waste (Mckendry 2002). However, biomass has a low energy density and therefore at present it is more economical to use it simultaneously with coal. Pyrolysis is a process that has been used since the start of the industrial revolution for the large scale destructive distillation of coal to produce valuable char products. It can also be applied to other feedstock such as oil shale and other carbonaceous materials (Karrick 1934). Biomass is a promising alternative commercial fuel source but has a major drawback due to its low energy density. This has inspired a number of studies on the simultaneous use of coal and biomass such as co-pyrolysis (Meesri and Moghtaderi 2002; Kirtania and Bhattacharya 2013; Azizi et al. 2017; Baloyi and Dugmore 2019). In most of the studies, researchers seek to understand the pyrolysis kinetics and interactions between coal and biomass during co-pyrolysis. There are three possible scenarios that can occur during co-pyrolysis of coal and biomass which can be attributed to the existence or nonexistence of interactions between the two materials. The process parameters can manifest as values that are equal, less or more than a proportional sum of the individual materials. The latter is commonly referred to as synergistic effect (Quan and Gao 2016). Pyrolysis is a complex solid decomposition process that is composed of simultaneous and consecutive fluid-solid reactions. Allowing two different materials (coal and biomass) to decompose simultaneously can result in a more complex scenario where the reactions attributed by the individual materials affect one another. However, the causes of interactions and therefore, synergistic effects are not yet clearly understood by researchers. Quan and Gao (2016) proposed three possible mechanisms that are based on (i) the enhancement of the hydrogen transfer reaction due to the high hydrogen to carbon $(\mathrm{H} / \mathrm{C})$ ratio of biomass which generates more hydrogen and other light compounds that then alter the thermal behaviour of coal, (ii) pyrolysis catalysis due to the considerably large amount of alkali and alkaline earth metallic species in biomass, and (iii) the improvement of heat transfer properties for coal due to the heat from the low temperature biomass exothermic decomposition reactions. A number of researchers have attempted to study copyrolysis kinetics and how the individual reactions from coal and biomass interact and affect each other. The findings of these studies have generated controversy because a considerable number of researchers have reported synergistic effects whilst others observed that the interactions have an additive effect proportional to the coal/biomass ratio. For example, Wu et al. (2019) studied the co-pyrolysis of a low rank coal and algal biomass. The work focussed specifically on the kinetic characteristics of the volatile products. Synergistic effects were reported for the formation of $\mathrm{CO}_{2}$. The presence of algal biomass lowered the activation energy for reactions that result in the formation of $\mathrm{CO}_{2}$. Bhagavatula et al. (2016) studied synergistic effects in the co-pyrolysis of lignite and subbituminous coals with different kinds of biomass. It was observed that the activation energy distributions for the copyrolysis followed a different pattern from the expected theoretical ones. However, a number of researchers have presented results that suggest that there are no synergistic effects in the co-pyrolysis of coal and biomass. The effects observed in their works were a proportional summation of the individual effects (Kastanaki et al. 2002; Meesri and Moghtaderi 2002; Vuthaluru 2003; Kirtania and Bhattacharya 2013; Baloyi and Dugmore 2019). Interestingly, in their works, Aziz et al. (2017) and Chen et al. (2012) observed inhibitive effects.

This work seeks to explore the co-pyrolysis of coal and algal biomass. Firstly, an understanding of the pyrolysis behaviour of the individual substances is sought, thereby creating a foundation for decomposition models. Secondly, the co-pyrolysis behaviour is explored using experimental and modelling results. Comparison of the two sets of results allows for the investigation of the existence of coal/ algae interactions that result in synergistic effects. Thirdly, a pyrolysis kinetics analysis of the experimental results is used to further the understanding of the co-pyrolysis behaviour and further corroborate the conclusions obtained when investigating coal/algae interactions. Similar work that has been presented so far differs either in methodology or results obtained (Kastanaki et al. 2002; Meesri and Moghtaderi 2002; Vuthaluru 2003; Kirtania and Bhattacharya 2013).

The strategy employed in this work involves using suitable software to deconvolute experimental mass-loss data of coal and algae into mass-loss curves of their major constituents. The models are then used to generate massloss curves for different coal-algae blends. The generated mass-loss curves for blends are checked against the experimental data for any differences that may be used as evidence of synergistic effects attributed to coal/algae interactions. The application of computers and their software in modelling and simulation has already been demonstrated by a number of researchers in their different fields of study (Csukás et al. 2013; Nyoni et al. 2017; Wu and Li 2014). Secondly, a kinetic study on the co-pyrolysis of coal and algae is carried out. There are two common approaches to pyrolysis kinetics analysis; (1) model fitting and (2) model free methods (Mabunda and Meyer 2015). The difference between the approaches is that model fitting techniques require an assumption of the order of reaction before the evaluation of kinetic parameters such as the activation energy, rate constant and half-life. Whereas, model free methods known as iso-conversional methods 
can predict the kinetic parameters without knowledge of the order of reaction. The Coats-Redfern method is a common model fitting technique that can be used to evaluate kinetic parameters from a single mass loss curve if a reaction order is guessed accurately (Coats and Redfern 1964; Ebrahimi-Kahrizsangi and Abbasi 2007; Ramukutty and Ramachandran 2014). For this reason, the CoatsRedfern model fitting technique will be used for this study.

\section{Experimental}

\subsection{Materials}

Bituminous coal was obtained from a local coal merchant in Port Elizabeth, South Africa. Algae was cultured by use of photo-bioreactors at Innoventon, Downstream Chemicals Technology Station, Nelson Mandela University (NMU), Port Elizabeth, South Africa. Blends of coal and microalgae were prepared by mixing a known amount of coal with algae (Scenedesmus sp.) slurry of known solids concentration. The resultant paste was centrifuged and then dried in an oven overnight at $60{ }^{\circ} \mathrm{C}$. Proximate analyses of coal, algae and coal-algae samples was performed using a Macro TGA (ELTRA Thermostep) that was programmed to follow the procedure outlined in the ASTM standard method D7582 (ASTM 2011). Ultimate analysis of coal and algae was performed using an elemental analyser (Elementar, vario EL cube). The calorific value was determined by using a bomb calorimeter (Leco AC 600).

\subsection{Thermo-gravimetric analysis}

Thermo-gravimetric analysis (TGA) was performed using a thermo-gravimetric analyser (TA Instruments, Discovery TGA-5500). Each sample underwent a temperature ramp from an initial instrument temperature to a set final temperature of $800{ }^{\circ} \mathrm{C}$ at a heating rate of $10{ }^{\circ} \mathrm{C} / \mathrm{min}$ under inert conditions. Inert conditions were achieved by pushing nitrogen at a flowrate of approximately $80 \mathrm{~mL} / \mathrm{min}$. The coal-algae blends explored in this study contained $10 \%$, $20 \%$ and $40 \%$ algal biomass (sample IDs CA10, CA20 and CA40 respectively).

\subsection{Modelling for kinetic and synergistic study}

Mass-loss data generated by TGA was decoded into derivative thermo gravimetric mass-loss (DTG) curves using TA Instruments, Universal Analysis 2000 software. DTG curves express the relationship between the instantaneous reactivity ( $y$-axis) and temperature ( $x$-axis). Instantaneous reactivity, in this study, is defined as the rate of mass loss for a given heating rate (Eq. (1)).
Instantaneous reactivity can be used as an indicator of how fast a solid decomposes. In order to model the DTG curves as accurate as possible, deconvolution of spectral data was employed. Since most DTG curves for coal and biomass have visible peaks that can be confirmed with data from literature, it is possible to use suitable software to deconvolute the individual peaks into elements that are described by a suitable mathematical function, in this case, the Gaussian distribution. Depending on the accuracy of the deconvolution process, the deconvoluted curves can represent individual compounds that contribute to the overall DTG plot. Deconvolution of the experimental DTG plots into a series of Gaussian distributions was performed by making use of OriginPro ${ }^{\mathrm{TM}}$. OriginPro ${ }^{\mathrm{TM}}$, created by OriginLab Corporation, is a powerful data analysis program that has capabilities of plotting and deconvoluting several kinds of spectral data.

$Y=\frac{W_{\mathrm{i}}-W_{\mathrm{f}}}{\left[t_{\mathrm{f}}-t_{\mathrm{i}}\right] \beta}$

where $W_{\mathrm{i}}$ and $W_{\mathrm{f}}$ are the sample mass fractions (\%) at an instantaneous time period $\left(t_{\mathrm{f}}-t_{\mathrm{i}}\right)$ and $\beta$ is the heating rate $\left({ }^{\circ} \mathrm{C} / \mathrm{min}\right)$.

\subsection{Kinetic study}

For the reasons already mentioned, the Coats-Redfern integral method was used to fit first and second order kinetics into the experimental and model data. Heterogeneous decomposition of a fuel sample to form gaseous products and char can be expressed as a function of conversion as follows:

$\frac{\mathrm{d} X}{\mathrm{~d} t}=k f(X)$

where, $k$ is the rate constant; $X$ is the fraction of solid that has decomposed at time $t$.

Mathematical manipulation according to the CoatsRedfern method gives Eqs. (3) and (4) for first and second order kinetics respectively (Coats and Redfern 1964).

$\operatorname{In}\left[\frac{-\operatorname{In}(1-X)}{T^{2}}\right]=\operatorname{In} \frac{A R}{\beta E_{\mathrm{a}}}\left[1-\frac{2 R T}{E}\right]-\frac{E_{\mathrm{a}}}{R T}$
$\operatorname{In}\left[\frac{(1-X)^{-1}-1}{T^{2}}\right]=\operatorname{In} \frac{A R}{\beta E_{\mathrm{a}}}\left[1-\frac{2 R T}{E}\right]-\frac{E_{\mathrm{a}}}{R T}$

where $T$ is the absolute temperature $(\mathrm{K}) ; A$ is the pre-exponent factor in the Arrhenius equation; $R$ is the universal gas constant $\left(0.0083 \mathrm{~kJ} /\left(\mathrm{mol}^{\circ} \mathrm{C}\right)\right)$ and $E_{\mathrm{a}}$ is the activation energy $(\mathrm{kJ} / \mathrm{mol})$.

$X=\frac{W_{\mathrm{i}}-W}{W_{\mathrm{i}}-W_{\mathrm{f}}}$

where $W$ is the instantaneous mass fraction. 
The first term on the right hand side of Eqs. (3) and (4) can be regarded as a constant because the value of $\frac{2 R T}{E_{\mathrm{a}}}$ is negligible (Ebrahimi-Kahrizsangi and Abbasi 2007; Ramukutty and Ramachandran 2014). Therefore, a plot of the term on the left hand side against the reciprocal of the temperature should give a straight line. The pyrolysis kinetic parameters, that is, the activation energy and the pre-exponential factor $(A)$ can then be evaluated from the slope and $y$-intercept of the resultant plot, respectively. Furthermore, the rate constant $k$ can be calculated by Eq. (6). In this case, $T$ is taken as the mean experimental temperature (Ramukutty and Ramachandran 2014)

$k=A e^{\frac{-E_{\mathrm{a}}}{R T}}$

\section{Results and discussion}

\subsection{Proximate and ultimate analyses}

The proximate properties of coal, algae and their blends are shown in Table 1. Compared to coal, it is clear that algal biomass has a considerably higher volatile matter and lower carbon content. Therefore, algal biomass is expected to be the easier material to decompose, this normally manifests as high pyrolysis instantaneous reactivity. Furthermore, proximate properties of the three coal-algae blends reveal that blending of coal with algal biomass results in a composite material that has proximate properties that can be calculated from their parent materials by way of weighted averages. The ultimate analysis of coal and algal biomass presented in Table 2 gives us an insight on how the co-pyrolysis might take place. Generally, the low oxygen to carbon $(\mathrm{O} / \mathrm{C})$ and high $\mathrm{H} / \mathrm{C}$ molar ratios of algal biomass is an indication of large amounts of aliphatic hydrocarbons and low amounts of polar compounds, respectively. This implies that the pyrolysis of algal biomass will generally generate considerably large amounts of light gases and hydrocarbons such as $\mathrm{CO}, \mathrm{CO}_{2}, \mathrm{H}_{2}$ and $\mathrm{CH}_{4}$. Therefore, the high $\mathrm{H} / \mathrm{C}$ ratio can be considered as a strong indicator of the high likelihood of coal/algae interactions during co-pyrolysis. It has been highlighted that the enhancement of the hydrogen transfer reaction due to the

Table 1 Proximate analysis of coal, algae and their blends (as received)

\begin{tabular}{lrrrrr}
\hline Item & Coal & CA10 & CA20 & CA40 & Algae \\
\hline Moisture (\%) & 2.8 & 3.7 & 4.8 & 6.5 & 12.1 \\
Volatiles (\%) & 20.9 & 25.3 & 30.5 & 42.1 & 75.2 \\
Ash (\%) & 16.2 & 16.0 & 15.1 & 12.5 & 5.6 \\
Fixed carbon (\%) & 60.1 & 55.0 & 49.6 & 38.9 & 7.1 \\
\hline
\end{tabular}

Table 2 Ultimate and energy properties of coal and algae (dry ash free basis)

\begin{tabular}{lcc}
\hline Item & Coal & Algae \\
\hline Carbon (\%) & 63.6 & 45.6 \\
Hydrogen (\%) & 3.64 & 6.50 \\
Nitrogen (\%) & 1.57 & 11.1 \\
Sulphur (\%) & 0.49 & 0.48 \\
Oxygen (\%) & 30.7 & 36.3 \\
O/C molar ratio & 0.36 & 0.60 \\
H/C molar ratio & 0.69 & 1.71 \\
Calorific value $(\mathrm{MJ} / \mathrm{kg})$ & 27.8 & 23.4 \\
\hline
\end{tabular}

high $\mathrm{H} / \mathrm{C}$ ratio of biomass generates more hydrogen and other light compounds that interact with coal.

\subsection{Pyrolysis behaviour of coal and microalgae}

Figure 1 shows mass-loss and DTG curves for coal, algae and their blends. There are a number insights that can be gained from Fig. 1. The DTG curves of coal and algae reveal major differences in their pyrolysis characteristics. One obvious difference is the high instantaneous reactivity of algae (5 times) compared to that of coal. This observation is attributed to the generally high volatile content of algal biomass. It is also observed that algae decomposition occurred in the temperature range of $200-700{ }^{\circ} \mathrm{C}$, whilst that of coal occurred from 300 to beyond $800{ }^{\circ} \mathrm{C}$. Coal displays a slow decomposition curve with two distinct decomposition peaks at approximately 440 and $750{ }^{\circ} \mathrm{C}$, a transition hump appears at approximately $580{ }^{\circ} \mathrm{C}$. Algae displays two distinct peaks at approximately 280 and $600{ }^{\circ} \mathrm{C}$. The peaks in the decomposition of coal have been identified by various authors as the decomposition of aliphatic and carboxylic groups at lower temperatures and aromatic groups at higher temperatures (Kirtania and Bhattacharya 2013; Wang et al. 2015; Baloyi and Dugmore 2019). For algae, the peak at $280{ }^{\circ} \mathrm{C}$ corresponds to the decomposition of proteins. The overlapping peaks at 500-650 ${ }^{\circ} \mathrm{C}$ correspond to the decomposition of polymeric carbohydrate molecules and lipids (Kirtania and Bhattacharya 2013; Azizi et al. 2017).

As expected, the mass loss curves for the coal-algae blends lie in between the two curves for coal and algae. Furthermore, the DTG for coal-algae blends shows three distinct peaks, the first peak is mostly likely due to the decomposition of algae because it appears a temperature that is below the coal pyrolysis temperature of $300{ }^{\circ} \mathrm{C}$. The other two peaks are as a result of the simultaneous pyrolysis of coal and algae at higher temperatures. However, 

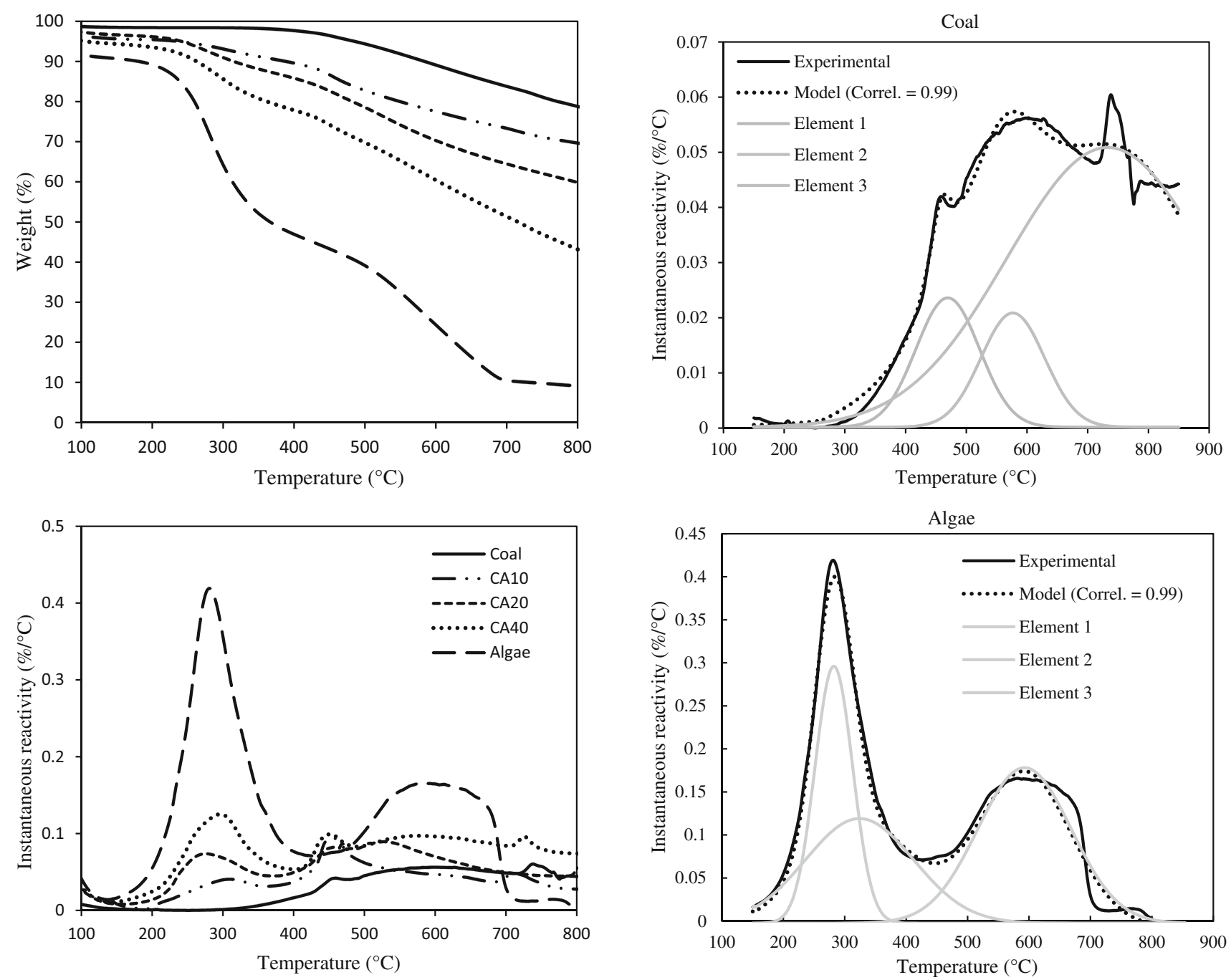

Fig. 1 Mass-loss and DTG curves for coal, algae and their blends

closer look into the DTG curves reveals that there might be some interactions between coal and algae at higher temperatures. This is evidenced by higher temperature peaks which follow an unexpected profile. Interestingly, coal-algae DTG curves display a sharp peak at approximately $460{ }^{\circ} \mathrm{C}$. This peak does not appear on the algae DTG but corresponds to a peak that appears on the coal DTG curve, however the same peak on coal shows a lower instantaneous reactivity of approximately $0.042 \% /{ }^{\circ} \mathrm{C}$ compared to $0.093 \% / \mathrm{C}$ on CA10. The peak that was expected to lie in between the coal and algae peaks $\left(0.042-0.07 \% /{ }^{\circ} \mathrm{C}\right)$ lies above the two. This observation affirms the existence of interactions between coal and algal biomass components during pyrolysis.

\subsection{DTG models}

The DTG models generated by use of OriginPro $^{\mathrm{TM}}$ are shown in Fig. 2. The model plots show high correlation

Fig. 2 Experimental and model DTG plots for coal and algae (with deconvoluted plots for constituent compounds) at $10{ }^{\circ} \mathrm{C} / \mathrm{min}$

coefficient which implies a good agreement with the experimental data $\left(R^{2}>0.99\right)$. However, the model plot for coal fails to show the second decomposition stage which appears as a distinct peak on the experimental data. This failure can be attributed to the nature and limitations of the Gaussian function used for deconvolution. There are three types of plots that appear on Cartesian plane in Fig. 2, namely, the plot from experimental TGA data, the fitted model and the Gaussian elements that make up the fitted model. Similarly to other works, the Gaussian elements are used to represent DTG curves for the decomposition of individual components that constitute the bulk of the material as shown in Fig. 2 (Kastanaki et al. 2002; Bach and Chen 2017; Wang et al. 2017; Chen et al. 2018). For instance, Chen et al. (2018) used deconvoluted curves to represent experimental DTG curves as individual elements that describe the decomposition of proteins, carbohydrates and lipids that constitute algae. In this study, the 
deconvolution was performed in such a way that the elements generated correspond to the major compounds that constitute coal and algal biomass. For algae, the compounds are proteins, carbohydrates and lipids that decompose at approximately 280,320 and $580{ }^{\circ} \mathrm{C}$ respectively (Bach and Chen 2017; Wang et al. 2017; Chen et al. 2018). However, coal displays a complex decomposition process but there is a general agreement amongst researchers that the compounds that decompose are mainly aliphatic, carboxylic and aromatic groups (Kastanaki et al. 2002; Kirtania and Bhattacharya 2013; Wang et al. 2015; Baloyi and Dugmore 2019). From the TG and DTG curves (Fig. 1) it can be deduced that the coal sample's crystalline structure undergoes softening into the plastic phase before the major devolatilisation stage. This process occurs at temperatures up to $460{ }^{\circ} \mathrm{C}$ and can be exothermic because it involves rearrangement and new bonds being formed. The DTG peak that shows at approximately $460{ }^{\circ} \mathrm{C}$ corresponds to the decomposition or cracking of large aliphatic compounds. From 500 to $700{ }^{\circ} \mathrm{C}$, further decomposition of phenolic and other oxygen containing compounds occurs slowly (no sharp peaks in this temperature range). Lastly, the remaining semi-char is heated to temperatures above $700{ }^{\circ} \mathrm{C}$ resulting in poly-condensation reactions involving aromatic compounds. The volatile by-products of polycondensation are driven off and this is manifested by a further mass loss (peak at approximately $750{ }^{\circ} \mathrm{C}$ ). (Kastanaki et al. 2002; Wang et al. 2015).

\subsection{Evaluation of synergistic effects}

For the evaluation of synergistic effects, the component curves from coal and algal biomass DTG models were added proportionately so as to generate the calculated and expected DTG plots for coal-algae blends at different ratios. Figure 3 shows a comparison of DTG curves for coal-algae blends obtained from experimental data and the calculated models. It is clear for all three scenarios that the calculated models fit well with the first stage decomposition but fails to describe the second and third stages. Generally, the calculated models do not fit well with the overall experimental data. The failure for the calculated model to fit with experimental data suggests that the experimental DTG curves are not a proportionate summation of the elements. This implies that there are interactions between algae and coal during co-pyrolysis. This observation is consistent with the works of various researchers (Shui et al. 2011; Chen et al. 2012; Bhagavatula et al. 2016; $\mathrm{Wu}$ et al. 2019). The interactions between algae and coal may result in positive (synergistic) or negative (inhibitive) effects on the individual pyrolysis of the materials. The first stage decomposition $\left(200-350{ }^{\circ} \mathrm{C}\right)$, which most likely corresponds to the pyrolysis of proteins and carbohydrates
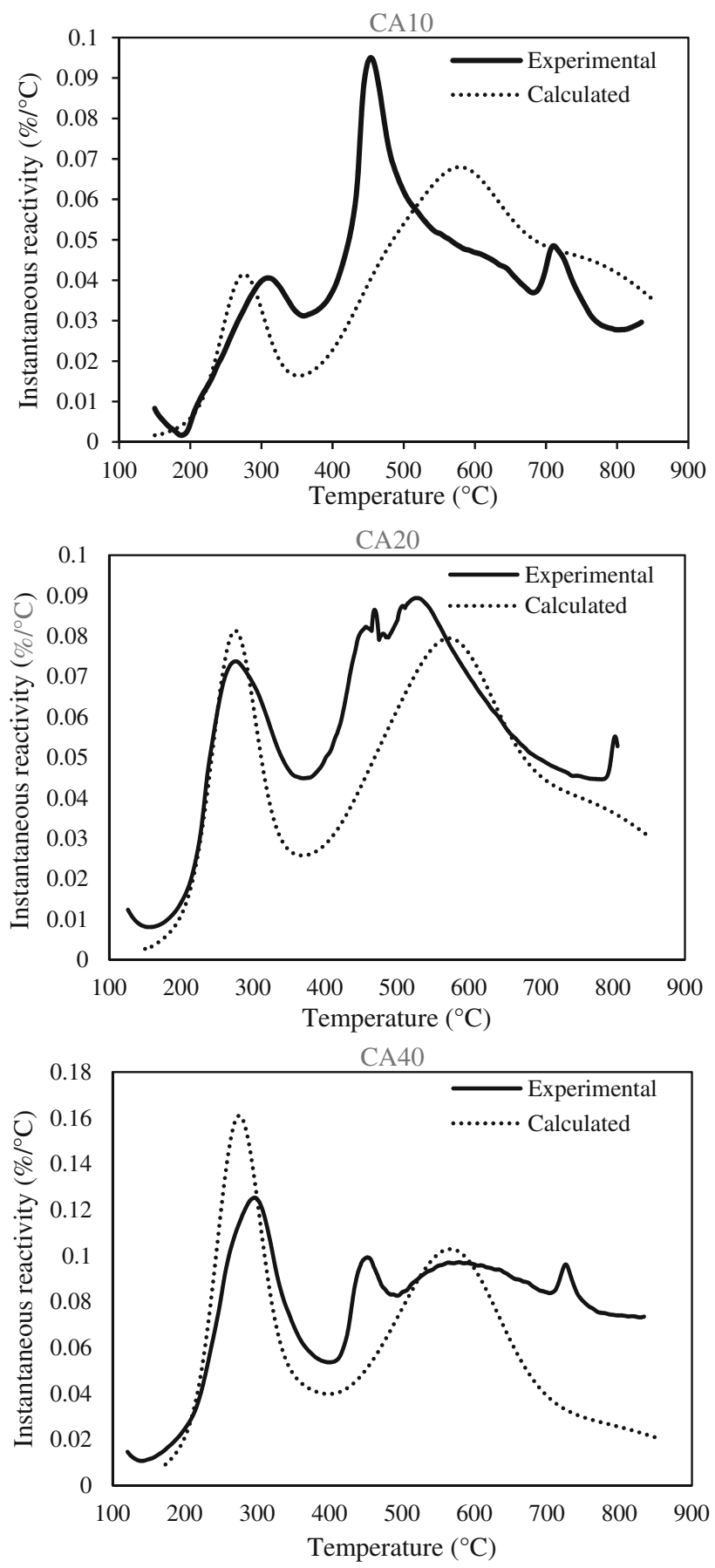

Fig. 3 DTG plots of different coal-algae blends at $10{ }^{\circ} \mathrm{C} / \mathrm{min}$

in algae, shows lower reactivity than the calculated ones for all the three algae/coal ratios. This implies that the presence of coal has an inhibitive effect on the decomposition reactivity of proteins and carbohydrates in algae. This observation can be attributed to a change in the heat and mass transfer properties that tend to slightly increase the resistance to various transport phenomena. The second and third decomposition stages $\left(400-600{ }^{\circ} \mathrm{C}\right.$, and $>700{ }^{\circ}$ $\mathrm{C}$, respectively), which largely correspond to the 
simultaneous decomposition of polymeric carbohydrates and lipids in algal biomass and the poly-condensation of the bulk of the aromatic compounds in coal, commences at lower temperatures for CA10 and CA20, than expected and shows higher reactivity. However, this is not the case with CA40, this observation is evidence that the magnitude of synergistic effects depend on the blending ratio. The synergistic effects that have been highlighted can be explained using Quan and Gao's (2016) hydrogen transfer reaction mechanism. Since the coal used in this study is caking coal (mainly used as feedstock in coke ovens), in the temperature range $400-500{ }^{\circ} \mathrm{C}$ the coal sample is expected to turn into plastic phase (Tran et al. 2018). The decomposition of polymeric carbohydrates in algal biomass generates light volatile compounds like $\mathrm{CO}, \mathrm{CO}_{2}, \mathrm{H}_{2}$ and $\mathrm{CH}_{4}$. These gases can interact with coal and alter its plasticity thereby affecting heat and mass transfer phenomena. Furthermore, hydrogen radicals generated from the de-amination of proteins together with metals found in the coal/algae crystalline structures that act as catalyst, promote the demethoxylation of aromatic compounds (Wu et al. 2017). As a result, synergistic effects manifest as the bulk of the material tends to decompose faster and at a lower temperature than expected.

\subsection{Decomposition kinetics}

Linear plots of Eqs. (3) and (4) (not shown) made it possible to evaluate pyrolysis kinetics parameters from each of the samples' experimental and modelled mass loss data.
The results are presented in Table 3. The calculated (generated from model) kinetic parameters for the pure substances, coal and algae compare well with the experimental ones. However, there is considerable error between the calculated parameters and those obtained via experiments. It is clear that the first stage decomposition of coal and algae fits well with second order kinetics (high $R^{2}$ values displayed in Table 3), activation energies evaluated at 81.8 and $145.5 \mathrm{~kJ} / \mathrm{mol}$. Furthermore, the second stage decomposition of coal fits well with second order kinetics with activation energy evaluated at $649.3 \mathrm{~kJ} / \mathrm{mol}$. However, second stage decomposition of algae fits well with the first order kinetics, activation energy evaluated at $127.3 \mathrm{~kJ} / \mathrm{mol}$. Coal-algae blends display a three stage decomposition process. Generally, the calculated kinetic parameters are different from the ones obtained by analysis of experimental mass-loss data. This implies that in this case, the DTG models that are based on proportionate contributions of coal and algae during co-pyrolysis are erroneous. This is attributed to the existence of interactions between coal and algae which results in an altered DTG curve that eventually gives different kinetic parameters. For the studied coal/ algae ratios, the kinetics of all the three decomposition stages fits well with second order. The activation energies evaluated are in the ranges of 131-138, 72-78 and $864.5-1235 \mathrm{~kJ} / \mathrm{mol}$ for first, second and third stages, respectively. The magnitudes of the coal-algae decomposition activation energies for each of the stages can be corresponded with the different stages in the decomposition of the parent materials. Therefore, from the results it

Table 3 Experimental versus calculated first and second-order fit and kinetic parameters for the pyrolysis of coal, algae and their blends at $10^{\circ} \mathrm{C} / \mathrm{min}$

\begin{tabular}{|c|c|c|c|c|c|c|c|c|c|c|c|c|}
\hline \multirow[t]{3}{*}{ Item } & \multicolumn{4}{|c|}{ Stage 1} & \multicolumn{4}{|c|}{ Stage 2} & \multicolumn{4}{|c|}{ Stage 3} \\
\hline & \multicolumn{2}{|c|}{ Experimental } & \multicolumn{2}{|c|}{ Calculated } & \multicolumn{2}{|c|}{ Experimental } & \multicolumn{2}{|c|}{ Calculated } & \multicolumn{2}{|c|}{ Experimental } & \multicolumn{2}{|c|}{ Calculated } \\
\hline & $\begin{array}{l}\text { Plot } \\
R^{2}\end{array}$ & $\begin{array}{l}E_{\mathrm{a}} \\
(\mathrm{kJ} / \mathrm{mol})\end{array}$ & $\begin{array}{l}\text { Plot } \\
R^{2}\end{array}$ & $\begin{array}{l}E_{\mathrm{a}} \\
(\mathrm{kJ} / \mathrm{mol})\end{array}$ & $\begin{array}{l}\text { Plot } \\
R^{2}\end{array}$ & $\begin{array}{l}E_{\mathrm{a}} \\
(\mathrm{kJ} / \mathrm{mol})\end{array}$ & $\begin{array}{l}\text { Plot } \\
R^{2}\end{array}$ & $\begin{array}{l}E_{\mathrm{a}} \\
(\mathrm{kJ} / \mathrm{mol})\end{array}$ & $\begin{array}{l}\text { Plot } \\
R^{2}\end{array}$ & $\begin{array}{l}E_{\mathrm{a}} \\
(\mathrm{kJ} / \mathrm{mol})\end{array}$ & $\begin{array}{l}\text { Plot } \\
R^{2}\end{array}$ & $\begin{array}{l}E_{\mathrm{a}} \\
(\mathrm{kJ} / \mathrm{mol})\end{array}$ \\
\hline \multicolumn{13}{|c|}{ 1st order kinetics } \\
\hline Coal & 0.93 & 60.6 & 0.94 & 59.5 & 0.99 & 283.9 & - & - & - & - & - & - \\
\hline CA10 & 0.98 & 96.5 & 0.99 & 96.2 & 0.93 & 43.5 & 0.99 & 64.7 & 0.95 & 857.3 & - & - \\
\hline CA20 & 0.99 & 81.3 & 0.99 & 94.3 & 0.92 & 61.6 & 1.00 & 77.8 & 0.98 & 671.1 & - & - \\
\hline CA40 & 0.98 & 96.0 & 0.97 & 98.2 & 0.92 & 58.5 & 0.99 & 66.3 & 0.97 & 591.7 & - & - \\
\hline Algae & 0.96 & 100.0 & 0.96 & 100.3 & 0.99 & 127.3 & 0.99 & 130.5 & - & - & - & - \\
\hline \multicolumn{13}{|c|}{ 2nd order kinetics } \\
\hline Coal & 0.97 & 81.8 & 0.97 & 80.6 & 1.00 & 649.3 & - & - & - & - & - & - \\
\hline CA10 & 0.99 & 131.9 & 0.97 & 141.7 & 0.94 & 77.9 & 0.99 & 95.9 & 0.97 & 1235 & - & - \\
\hline CA20 & 0.99 & 130.3 & 0.99 & 149.8 & 0.95 & 74.2 & 1.00 & 102.8 & 0.99 & 925.1 & - & - \\
\hline CA40 & 0.99 & 137.6 & 1.00 & 146.0 & 0.96 & 72.6 & 1.00 & 87.8 & 0.98 & 864.5 & - & - \\
\hline Algae & 0.99 & 145.5 & 0.99 & 147.0 & 0.94 & 227.8 & 0.93 & 237.5 & - & - & - & - \\
\hline
\end{tabular}


can be deduced that the first stage coal-algae decomposition is dominated by the individual decomposition of algae, the second and third stages correspond to coal decomposition. (Bhagavatula et al. 2016). It is interesting to note that the magnitude of the activation energy for the first stage decomposition of coal-algae blends lies between that of the first and second stage decomposition of algae. This observation indicates that co-pyrolysis forces the first and second stage decomposition of algae to occur at the same time. Furthermore, the second stage decomposition of coalalgae blends is dominated by the individual pyrolysis of coal, but with lower activation energy. Synergistic effects manifest as a decrease in activation energy. This observation has been explained via the hydrogen transfer reaction mechanism. The kinetic parameters obtained in this work are comparable with that obtained by Kirtania and Battachrya (2013) and Bhagavatula et al. (2016).

\section{Conclusion and Outlook}

This study investigated the co-pyrolysis behaviour and kinetics of bituminous coal and microalgae. Modelling and kinetic study methods were used to detect the existence of interactions between coal and microalgae during pyrolysis. The study managed to present the co-pyrolysis kinetics and further showed that indeed interactions do exist. In light of the current debate on the existence and mechanisms of interactions between coal and biomass during co-pyrolysis, this study is expected to be a positive contribution to the debate and knowledge resource.

Acknowledgements The authors would like to acknowledge the contribution to this work by the staff at Innoventon, Downstream Chemicals Technology Station, Nelson Mandela University. Above all, this work is dedicated to the memory of the late Professor Ben Zeelie, founder of Innoventon.

Authors Contributions BN-PHD student doing the research. LBScientific officer (NMU), performed TGA on all samples. SD- Research technician (Innoventon), performed the deconvolution using Origin $\mathrm{Pro}^{\mathrm{TM}}$. SS-Co-supervisor. SPH-supervisor.

Funding This work is supported by Innoventon, Downstream Chemicals Technology Station and the Centre for Rubber Science and Technology, Nelson Mandela University.

\section{Compliance with ethical standards}

Conflict of interests Authors have no competing interests to declare.

Open Access This article is licensed under a Creative Commons Attribution 4.0 International License, which permits use, sharing, adaptation, distribution and reproduction in any medium or format, as long as you give appropriate credit to the original author(s) and the source, provide a link to the Creative Commons licence, and indicate if changes were made. The images or other third party material in this article are included in the article's Creative Commons licence, unless indicated otherwise in a credit line to the material. If material is not included in the article's Creative Commons licence and your intended use is not permitted by statutory regulation or exceeds the permitted use, you will need to obtain permission directly from the copyright holder. To view a copy of this licence, visit http://creativecommons. org/licenses/by/4.0/.

\section{References}

ASTM (2011) Standard test methods for proximate analysis of coal and coke by macro thermogravimetric analysis. ASTM, Pennsylvania, pp 1-3

Azizi K, Keshavarz M, Abedini H (2017) Characteristics and kinetics study of simultaneous pyrolysis of microalgae Chlorella vulgaris, wood and polypropylene through TGA. Bioresour Technol 243:481-491. https://doi.org/10.1016/j.biortech.2017.06.155

Bach Q, Chen W (2017) A comprehensive study on pyrolysis kinetics of microalgal biomass. Energy Convers Manag 131:109-116. https://doi.org/10.1016/j.enconman.2016.10.077

Baloyi H, Dugmore G (2019) Influences of microalgae biomass on the thermal behaviour of waste coal fines. J Energy South Africa 30:1-7. https://doi.org/10.17159/2413-3051/2019/v30i1a5452

Bhagavatula A, Shah N, Honaker R (2016) Estimating the pyrolysis kinetic parameters of coal, biomass, and their blends: a comparative study. Energy Fuels 30:10045-10054. https://doi. org/10.1021/acs.energyfuels.5b00692

Chen C, Ma X, He Y (2012) Co-pyrolysis characteristics of microalgae Chlorella vulgaris and coal through TGA. Bioresour Technol 117:264-273. https://doi.org/10.1016/j.biortech.2012. 04.077

Chen W, Chu Y, Liu J, Chang J (2018) Thermal degradation of carbohydrates, proteins and lipids in microalgae analyzed by evolutionary computation. Energy Convers Manag 160:209-219. https://doi.org/10.1016/j.enconman.2018.01.036

Coats A, Redfern J (1964) Kinetic parameters from thermogravimetric data. Nature 201:67-69

Csukás B, Varga M, Miskolczi N et al (2013) Simplified dynamic simulation model of plastic waste pyrolysis in laboratory and pilot scale tubular reactor. Fuel Process Technol 106:186-200. https://doi.org/10.1016/j.fuproc.2012.07.024

Ebrahimi-Kahrizsangi R, Abbasi MH (2007) Evaluation of reliability of coats-redfern method for kinetic analysis of non-isothermal TGA. Trans Nonferrous Met Soc China 18:217-221

Karrick L (1934) Process of destructively distilling solid carbonaceous material. US Patent 1958918A, pp 1-4

Kastanaki E, Vamvuka D, Grammelis P, Kakaras E (2002) Thermogravimetric studies of the behavior of lignite-biomass blends during devolatilization. Fuel Process Technol 78:159-166

Kirtania K, Bhattacharya S (2013) Pyrolysis kinetics and reactivity of algae-coal blends. Biomass Bioenerg 55:291-298. https://doi. org/10.1016/j.biombioe.2013.02.019

Mabunda A, Meyer E (2015) Model free kinetic analysis of biomass/sorbent blends for gasification purposes. Renew Sustain Energy Rev 53:1656-1664. https://doi.org/10.1016/j.rser.2015. 07.038

Mckendry P (2002) Energy production from biomass (part 1): overview of biomass. Bioresour Technol 83:37-46

Meesri C, Moghtaderi B (2002) Lack of synergetic effects in the pyrolytic characteristics of woody biomass/coal blends under low and high heating rate regimes. Biomass Bioenerg 23:55-66

Nyoni B, Hlabano-Moyo BM, Chimwe C (2017) Using a simulation software to perform energy and exergy analyses of the sulfur- 
iodine thermochemical process. Int J Model Simulation, Sci Comput 8:1-14. https://doi.org/10.1142/S1793962317500027

Quan C, Gao N (2016) Copyrolysis of biomass and coal: a review of effects of copyrolysis parameters, product properties, and synergistic mechanisms. Biomed Res Int 2016:1-11. https:// doi.org/10.1155/2016/6197867

Ramukutty S, Ramachandran E (2014) Reaction rate models for the thermal decomposition of ibuprofen crystals. J Cryst Process Technol 4:71-78. https://doi.org/10.4236/jcpt.2014.42010

Shui H, Shan C, Cai Z et al (2011) Co-liquefaction behavior of a subbituminous coal and sawdust. Energy 36:6645-6650. https://doi. org/10.1016/j.energy.2011.08.046

Tran QA, Stanger R, Xie W et al (2018) Impacts of mild pyrolysis and solvent extract on coking coal thermoplasticity. Energy Fuels 30:9293-9302. https://doi.org/10.1021/acs.energyfuels.6b02018

Vuthaluru HB (2003) Thermal behaviour of coal/biomass blends during co-pyrolysis. Fuel Process Technol 85:141-155. https:// doi.org/10.1016/S0378-3820(03)00112-7
Wang M, Li Z, Huang W et al (2015) Coal pyrolysis characteristics by TG-MS and its late gas generation potential. Fuel 156:243-253. https://doi.org/10.1016/j.fuel.2015.04.055

Wang X, Sheng L, Yang X (2017) Pyrolysis characteristics and pathways of protein, lipid and carbohydrate isolated from microalgae Nannochloropsis sp. Bioresour Technol 229:119-125. https://doi.org/10.1016/j.biortech.2017.01.018

Wu P, Li J (2014) Theoretical studies on the pyrolysis of (Thion)carbonates. J Theor Comput Chem 13:16-18. https://doi.org/10. 1142/S0219633614500515

Wu Z, Yang W, Tian X et al (2017) Synergistic effects from copyrolysis of low-rank coal and model components of microalgae biomass. Energy Convers Manag 135:212-225. https://doi.org/ 10.1016/j.enconman.2016.12.060

Wu Z, Li Y, Zhang B et al (2019) Co-pyrolysis behavior of microalgae biomass and low-rank coal: kinetic analysis of the main volatile products. Bioresour Technol 271:202-209. https:// doi.org/10.1016/j.biortech.2018.09.076 